
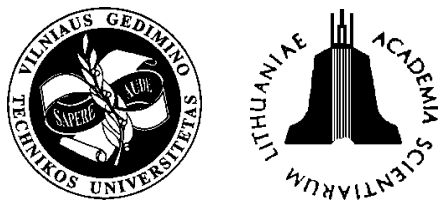

ISSN 1648-4142 TRANSPORT

\title{
THE INFLUENCE OF VEHICLES SPEED ON ACCIDENT RATES AND THEIR CONSEQUENCES
}

\author{
Alvydas Pikūnas ${ }^{1}$, Vidmantas Pumputis ${ }^{2}$, Vigilijus Sadauskas ${ }^{3}$ \\ Dept of Automobile Transport, Vilnius Gediminas Technical University, J. Basanavičiaus g. 28, \\ LT-03224 Vilnius-09, Lithuania. Tel. (8 5) 2744790
}

Received 2003-08-30; accepted 2004-01-15

\begin{abstract}
The purpose of this article is to identify the influence of vehicles speed on accident rates and their consequences. In general the desired speed depends on several factors such as speed limits, vehicle type, traffic density, road environment, road geometry, time, and driving experience. From traffic engineering point of view a drivers' desired speed is the speed, which drivers usually want to maintain in different traffic situations, but it's very important to create a safe environment for all participants of traffic. When traffic is heavy most drivers are in a platoon and the traffic situation is such that some drivers attempt to overtake the leading vehicle or adjust their speed to the vehicle in front. Drivers cannot achieve the desired speed during peak hours. During peak hours urban freeways usually have severe traffic congestion. The random variation of traffic also contributes to the fact that it is not always possible to maintain the speed which a driver desires.
\end{abstract}

Keywords: road traffic safety, accidents, speed, urban area, roads, factors.

\section{Introduction}

Each country sets its own speed limits, however rates are similar. In most European countries speed limit is 50 $\mathrm{km} / \mathrm{h}$, in some - up to $60 \mathrm{~km} / \mathrm{h}$, in the country-side 70 to $113 \mathrm{~km} / \mathrm{h}$, on motorways -80 to $130 \mathrm{~km} / \mathrm{h}$, except for the German motorways, where speed limit is of recommendation character. In the European countries speed limits are selected according to the country's accident rate and state politicians attitude to traffic safety problems. In the western states cities and settlements speed limit is $50 \mathrm{~km} / \mathrm{h}$, as the city has especially great danger to the pedestrians and bikers. As the speed increases danger for that group increases too. New wording of the Lithuanian traffic regulations fixes the speed limit of 50 $\mathrm{km} / \mathrm{h}$ in cities and settlements. General speed limits in the European states are given in Table 1.

Speed on Lithuanian roads is additionally limited in order to assure safe traffic, because of emergency places or dangerous sections of the road as well as in places where pedestrians walk. Speed limits are intended to decrease accident rate, to facilitate their consequences and to decrease transport costs.

Vehicle speed [1] is limited taking into account:

\footnotetext{
${ }^{1}$ vaida@ti.vtu.lt

${ }^{2}$ v.pumputis@transp.lt

${ }^{3}$ v.sadauskas@transp.lt
}

Table 1. General speed limits on European roads by vehicle category in $\mathrm{km} / \mathrm{h}$ urban areas $(\mathrm{GV})$ rural roads $(\mathrm{MK})$ motorways (AM)

\begin{tabular}{|c|c|c|c|c|c|c|}
\hline \multirow{2}{*}{ Country } & \multicolumn{3}{|c|}{ Vehicles } & \multicolumn{3}{c|}{ Trucks } \\
\cline { 2 - 7 } & GV & MK & AM & GV & MK & AM \\
\hline Austria & 50 & - & 130 & 50 & 70 & 80 \\
\hline Belgium & 50 & $90 / 120$ & 120 & 50 & 90 & 90 \\
\hline Denmark & 50 & 80 & 110 & 50 & 80 & 70 \\
\hline Finland & 50 & 100 & $80 / 100 / 120$ & 50 & 80 & 80 \\
\hline France & 50 & $50 / 100 / 110$ & $50 / 110 / 130$ & 50 & $50 / 80$ & $50 / 90$ \\
\hline Germany & 50 & 100 & $\begin{array}{c}\text { Reco- } \\
\text { mended }\end{array}$ & 50 & 80 & 80 \\
\hline Greece & 50 & 110 & 120 & 50 & 80 & 80 \\
\hline Italy & 50 & 90 & 130 & 50 & 70 & 80 \\
\hline Netherlands & 50 & 100 & 120 & 50 & 80 & 80 \\
\hline Portugal & 50 & $100 / 90$ & $110 / 120$ & 50 & 80 & 90 \\
\hline Spain & 50 & 100 & 120 & 50 & 80 & 90 \\
\hline Sweden & 50 & $90 / 110$ & 90110 & 50 & 90 & 90 \\
\hline G. Britain & 48 & - & 113 & 48 & - & 96 \\
\hline Czech & 60 & 90 & 130 & 50 & 80 & 80 \\
\hline Hungary & 50 & 100 & 120 & 50 & 70 & 80 \\
\hline Latvia & 50 & - & - & 50 & - & - \\
\hline Lithuania & 50 & 90 & $110 / 130$ & 50 & 70 & 90 \\
\hline Norway & 50 & $80 / 90$ & 90 & 50 & 80 & 80 \\
\hline Poland & 60 & 90 & 110 & 50 & 70 & 70 \\
\hline Romania & 60 & 80 & 80 & 40 & 50 & 50 \\
\hline Slovakia & 60 & 90 & 130 & 60 & 90 & 80 \\
\hline Switzerland & 50 & 100 & 120 & 50 & 80 & 100 \\
\hline
\end{tabular}

Source: ECMT $2002 \mathrm{~m}$. 
- type of the road;

- traffic intensity;

- rate of accidents;

- environment.

\section{The exceed of safe speed in Lithuania}

Drivers, having noticed a speed limiting sign, suppose it's too drastic, however, such signs often are in those sections of the road where many accidents were registered.

According to the information of the traffic police, each year about 1200 traffic accidents are caused by unsafe speed and as a result about 200 people are killed and about 1500 - injured. Table 2 shows the number of killed and injured because of unsafe speed, however, actually these figures are much greater. The traffic supervision authority states that because of unsafe speed as the secondary cause of the accident a half of accidents occur.

Table 2. Number of accidents, injured and killed people when driving speed was unsafe

\begin{tabular}{|l|c|c|c|c|c|}
\hline $\begin{array}{l}\text { Accidents and their } \\
\text { consequences / Years }\end{array}$ & $\mathbf{1 9 9 7}$ & $\mathbf{1 9 9 8}$ & $\mathbf{1 9 9 9}$ & $\mathbf{2 0 0 0}$ & $\mathbf{2 0 0 1}$ \\
\hline Number of accidents & 5319 & 6445 & 6356 & 5807 & 5972 \\
\hline $\begin{array}{l}\text { Number of accidents when } \\
\text { driving speed was unsafe }\end{array}$ & 909 & 1346 & 1462 & 1252 & 1350 \\
\hline Number of killed people & 725 & 829 & 748 & 641 & 706 \\
\hline $\begin{array}{l}\text { Number of killed people } \\
\text { when driving speed was } \\
\text { unsafe }\end{array}$ & 179 & 206 & 242 & 217 & 207 \\
\hline $\begin{array}{l}\text { Number of injured people } \\
\text { Number }\end{array}$ & 6198 & 7667 & 7696 & 6960 & 7103 \\
\hline $\begin{array}{l}\text { Number of killed people } \\
\text { when driving speed was } \\
\text { unsafe }\end{array}$ & 1730 & 2010 & 1861 & 1244 & 1864 \\
\hline
\end{tabular}

Source: $2002 \mathrm{~m}$.

According to the analysis of vehicle speed on rural roads and motorways performed in 2002 by the public institution "Transport and Road Investigation Institute":

- $\quad$ in 2001 (in comparison with 2000) a number of drivers exceeding the allowable speed slightly increased;

- $\quad$ in 2001 subject to the road type 20 to $50 \%$ of drivers exceed the allowable speed. In average a half of them exceeded speed by $10 \mathrm{~km} / \mathrm{h}$;

- $\quad$ on the motoway A1 Vilnius-Kaunas-Klapeda section Vilnius-Kaunas in 2001 50,1 \% of drivers exceeded the allowable speed (average traffic density is 15936 vehicles/ day). This situation may be explained by the fact that speed exceeding drivers deliberately influence other drivers.

Having analysed the information on vehicles speed on rural roads and motorways in 1998-2001 it may be stated that the following law of speed change prevails: a number of drivers exceeding the allowable speed increased in the first half of the year, later it decreased. Greater differences of yearly speed figures are evident at the beginning and at the end of the year. This is subject to meteorological conditions in winter.

\section{Speed influence upon braking distance and choice of safe speed}

Investigating speed influence upon the rate of accidents, the braking distance during driving at different speed must be analysed at first [2]. Let's analyse the experiment carried out by the scientistists of the Swedish Research Institute in order to determine the influence of speed upon the braking distance.

Three standard vehicles of different class and three drivers with a good reaction were chosen for the test. During tests an auxiliary obstacle was fixed in front of the running vehicle and the distance driven by the driver since the moment he noticed the obstacle (the distance driven by the driver since the moment he noticed the obstacle and pressed the brakes) as well as the braking distance (from the beginning to the end) were measured.

The results of three drivers were very similar. According to the average of the results a graph of the vehicle braking distance was prepared taking into account the driver's reaction road and vehicle braking distance. The test has shown the greater is speed, more time is needed to start stopping of the vehicle. As a result braking distance is longer. According to the graph (Fig 1) it may be exactly fixed when a slower driving vehicle will collide with more quickly driving vehicle, provided the drivers pressed brakes at the same moment. For example: two vehicles are driven at the speed of $60 \mathrm{~km} / \mathrm{h}$ and 80 $\mathrm{km} / \mathrm{h}$ respectively. Drivers notice the obstacle at the same time and press brakes. The driver driving the vehicle at the speed of $60 \mathrm{~km} / \mathrm{h}$ will stop after $\sim 35 \mathrm{~m}$ and the other driver - after $\sim 55 \mathrm{~m}$. The graph shows that at the time when the driver driving at the speed of $60 \mathrm{~km} / \mathrm{h}$ will stop the other driver will run at the speed of $60 \mathrm{~km} / \mathrm{h}$.

Assuming that the experiment was carried out with the standard average class vehicle the mathematical expression of the braking distance $\mathrm{S}_{\text {st. }}$ (meters) on the dry asphalt will be the following:

$$
S_{\text {st. }}=V \cdot R+0,00419 V^{2,0355}
$$

here: $R$ is the time of the braking system action and the time of the average reaction driver $0,3 \mathrm{~s}, V$ is average vehicle speed, $\mathrm{km} / \mathrm{h}$.

Each driver deliverately choosing speed is influenced by the speed limit [3]. As the driver notices speed limit he calculates the time needed to reach a destination place at the given speed. Not many drivers evaluate the 


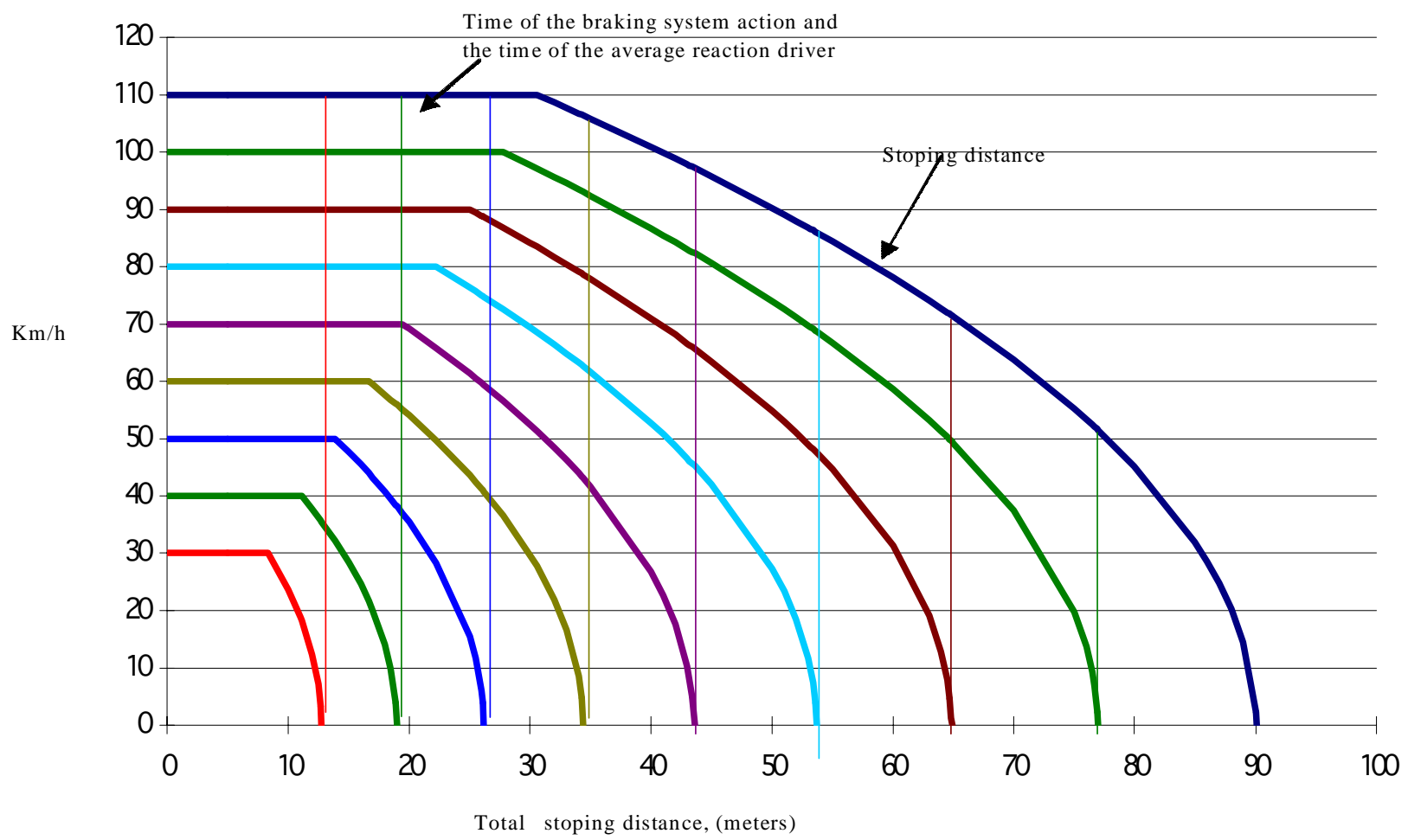

Fig 1. Average vehicle stopping distance (drivers reaction time and stopping distance)

fact that having chosen a greater speed they increase risk of accident, vehicle maintenance costs and environmental pollution. The factors most influencing driving speed are presented in Fig 2.

\section{The influence of speed control}

In each country police controls the driving speed and forces drivers to drive at the allowable speed. Control measures may be effective if the driver knows he is under control and may be imposed a penalty for violations of the traffic regulations [4]. Speed exceed and rate of accidents may be decreased by increasing traffic control as well as fixing automatic speed meters in places with great rate of accidents. The influence of speed con-

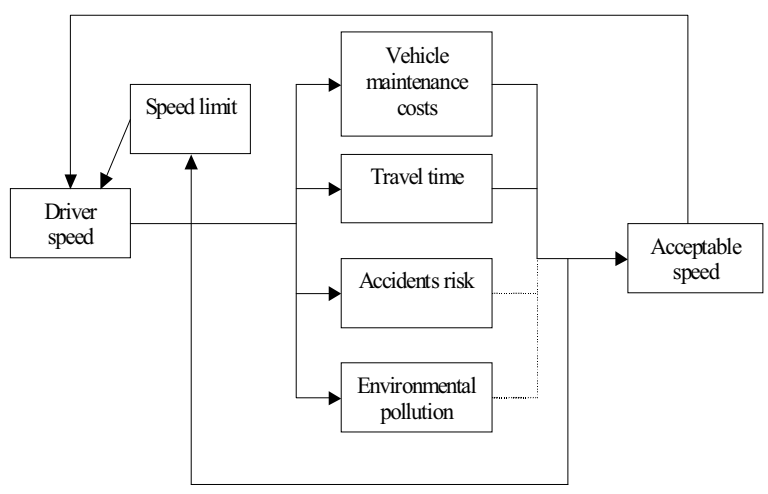

Fig 2. Factors most influencing driving speed trol often depends on the following factors:

- intensity of traffic participants control;

- effectiveness of penalty system;

- effectiveness of penalties;

- public announcement of violations;

- level of allowable speed exceed.

Based on these factors, Swedish scientists [5] produced a graph of the relationship between enforcement level and compliance with a speed limit, i.e. relationship of these parameters (Fig 3).

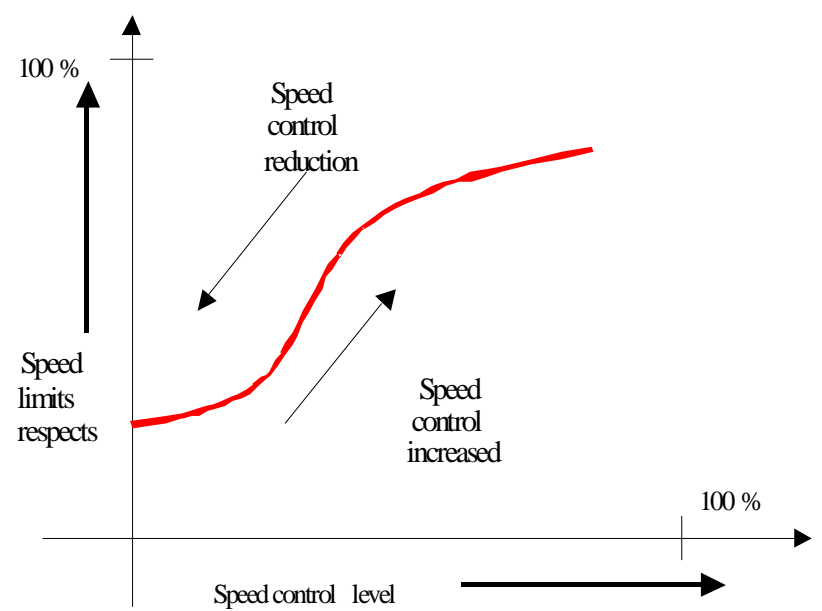

Fig 3. Relationship between enforcement level and compliance with a speed limit 
The effectiveness of traditional speed control measures depends on the effectiveness of speed meters. Usually, police officers measure speed by radars or speed observance cameras, however automatic speed control cameras may be used also. Deciding the choice of speed control measure, it is necessary to evaluate economic viability of the measure. Effective and costly traffic control measures are reasonable on high intensity roads or roads with high rate of accidents. In most of the countries speed control cameras are fixed on such roads as they enable to fix driving speed, time and place.

Various speed control measures enable to decrease speed exceed. However, the influence upon speed exceed is various. Investigations of speed control measures effectiveness performed by some countries show the following [6]:

- $\quad$ fixing of traffic safety improving measures near the schools, hospitals or other places where there are many pedestrians, may reduce speed by $5-20 \mathrm{~km} / \mathrm{h}$;

- experimental studies of automatic speed exceed warning signs (when the driver is given a warn of exceeding allowable speed) and speed control measures on certain sections of the road reduce speed by $2-8 \mathrm{~km} / \mathrm{h}$ and the probability of accidents decrease evidently;

- In Holland after increase of speed control in some city zones, average speed was reduced by $2-4 \mathrm{~km} / \mathrm{h}$ and the rate of accidents by $20 \%$.

- In Australian, city of Victoria, active speed measurement control, i.e. 2500 cameras and 54 automatic radars, which checked the speed of each vehicle nine times per month was installed and the society was notified of this. As a result average speed changed slightly, however, cases of high speed were reduced. In 5 years a number of collisions was reduced by $21 \%$, a number of hard injuries - by 38 $\%$ and a number of killed by $51 \%$.

- Occasional speed control reduces speed exceed slightly, however, a police automobile driving on the rural road reduces the speed of other vehicles in the average by $10 \mathrm{~km} / \mathrm{h}$.

\section{Trip time and driving speed evaluation}

Each driver before a trip calculates the distance and the speed to reach the destination place. Having analysed the deciding factors, i.e. average speed, conditions and traffic intensity as well as other factors, [7] influencing time of the trip, mathematical expression of the time of trip $T_{k}$ is the following:

$$
T_{k}=\frac{S}{\tau_{k} \cdot N_{k}+1+\tau_{j}},
$$

here: $S$-actual length of the trip, $\mathrm{km}, T_{k}$-average speed, when there is no traffic jams, $\mathrm{km} / \mathrm{h}, T_{j}$ - average speed during traffic jams, $\mathrm{km} / \mathrm{h}, N_{k}$ - traffic conditions constant (Table 3) 1.

Table 3. Traffic conditions constants

\begin{tabular}{|l|l|}
\hline $\begin{array}{l}\text { Meaning of the } \\
\text { constant }\end{array}$ & Traffic condition \\
\hline 1 & Dry road pavement, good visibility \\
\hline 0,9 & Dry road pavement, bad visibility \\
\hline 0,8 & Heavy rain, bad visibility \\
\hline 0,7 & Snow slippery pavement \\
\hline 0,6 & Especially bad traffic conditions \\
\hline
\end{tabular}

\section{The influence of vehicles speed on accident conse- quences}

The most important factors for the accidents rate on a concrete road are: speed limits, average driving speed, traffic volume intensity and structure and meaning of the road [8]. After the evaluation all these factors we created a formula for the prognosis of the numbers of accidents rate on a concrete road:

$$
A=(S) \cdot\left(V^{\prime}\right) \cdot(E) \cdot(G)
$$

here: $A$-possible number of accidents on a concrete road; $S$ - number of the accidents rate in last four years on the concrete road; $V^{\prime}$ - average driving speed in the concrete road; $E$ - constant of the traffic volume intensity; $G-$ constant of the structure and meaning of the road.

If there is no possibility to make the estimation of the real driving speed on the concrete road, it's possible to make the calculation of the average driving speed.

$$
V^{\prime}=V \cdot C v,
$$

here: $V$ - speed limits on the concrete road; $C v-$ speed constant (presented in Table 4).

Constant of the traffic volume intensity is:

$E=V^{\prime} / I$, here:

$I$ - traffic intensity in the concrete road, number of vehicle/24 hours;

Constant of the structure and meaning of the road:

Table 4. Averige traffic speed and traffic intensity constants

\begin{tabular}{|l|c|c|}
\hline \multicolumn{1}{|c|}{ Place } & Speed limits, $\mathrm{km} / \mathrm{h}$ & $\begin{array}{c}\text { Speed } \\
\text { coefficients, } C v\end{array}$ \\
\hline Urban roads & $50-60$ & 0,789 \\
\hline Suburban roads & From 70 up to 100 & 0,921 \\
\hline Other road & From 90 up to 130 & 1,075 \\
\hline
\end{tabular}




$$
G=\operatorname{ekp}\left[S g_{i} G_{i}\right]
$$

here: $g_{i}$ - length of the concrete road km; $G_{i}-$ constant of the road structure.

Speed coefficients are presented by the research results of the G. Britain road research institute [6].

After the analysis of the driving speed for the accidents consequences Swedish road transport and research institute (VTI) estimated the dependence between driving speed and their consequences:

- A pedestrian will be very seriously injured if a car driver will hit him with a speed from 30 up to 50 $\mathrm{km} / \mathrm{h}$, (seriousness of injure directly depends on the speed).

- In most case a pedestrian will be killed if a car driver will hit him with a speed higher than $50 \mathrm{~km} / \mathrm{h}$, (possibility to survive only about $2 \%$ )

- If a car driver will hit the driver or passengers doors with a higher speed than $50 \mathrm{~km} / \mathrm{h}$ there is no possibility for them to survive.

- If a car driver will hit the standing car with a higher speed than $50 \mathrm{~km} / \mathrm{h}$ there is no possibility for a driver to survive.

According to the research results in Sweden road designing standards special road safety standards are prepared. One of the main purpose of road safety measures is to reduce the speed up to safe speed for traffic users [9]. For example, in front of the most dangerous pedestrian crossing special road safety measures for the speed reduction to $30 \mathrm{~km} / \mathrm{h}$ are implemented. As the Swedish practise shows that only with the help of effective traffic safety measures it is possible to create safe environment for the all traffic users. Swedish road transport and research institute established that there is a direct relation between average driving speed and its consequences higher speed - harder consequences.

\section{Conclusions}

Having analysed the accidents occurred during the last years in Lithuania and their consequences subject to the speed of vehicles and the experience of the foreign countries, the following was concluded:

1. In progressive European cities speed limit is $50 \mathrm{~km} / \mathrm{h}$

2. Having evaluated primary and secondary reasons of accidents in Lithuania, it may be stated that almost $50 \%$ of accidents occur because of bad choice of safe speed.

3. On rural roads subject to the importance of the road 10 to $30 \%$ of drivers exceed the allowable speed.

4. If average speed in cities and settlements is decreased by $10 \mathrm{~km} / \mathrm{h}$, a number of accidents decreases by $20 \%$, a number of killed - by $30 \%$ and a number of injured - by $40 \%$.
5. If average speed is increased by $10 \mathrm{~km} / \mathrm{h}$, a number of accidents increases by $22 \%$, a number of killed by $50 \%$.

\section{References}

1. Bjornskau, T. Why are the 'safest' norms, attitudes and types of behaviour not typical for the safest drivers? Transport Reviews, 1996 March, p. 171-184.

2. Draskoczy, M.; Mocsari, T. Present Speeds and Speed Management Methods in Europe, 1997, p. 11.

3. Mackie, P. J.; Jara-Diaz, S.; Fowkes, A. S. The value of travel time saving in evaluation. Transport Research. Part E, 2001, p. 91-106.

4. Becker, W. Impact assessment of road safety campaigns. Transport Reviews, 1996 Sptember, p. 345-356.

5. Evans, W. Risk assessment by transport organisations. Transport Reviews, 1997 February, p. 145-163.

6. Allsop, R.E. Aspects of Speed in Relation to Traffic Safety. Traffic Engineering + Control, 1990 August, p. 88-103.

7. Noland, R. B. and Polak, J. W., Travel time variability: a review of theoretical and empirical issues. Transport Reviews, 2002, Vol 22, p. 39-53.

8. Baruya, A. A. Review of Speed - Accident Relationship for Europen Road, 1996, p. 19-21.

9. Sadauskas, V.; Pukalskas, S. Selection of optimal speed depending on accident data and ecology. Transport (Transportas), 2000, Vol XV, No 3, p. 133-137. 